\title{
Transitional Care for Patients with Portal Hypertension:A multicenter study of intervention for patients post-TIPS
}

Yin Xu

Shanghai Jiao Tong University Medical School Affiliated Ruijin Hospital Luwan Branch, Shanghai

Zhong-Min Wang ( $\nabla$ wzm11896@rjh.com.cn)

Ruijin Hospital

Ru-Mei Yang

Shanghai Jiao Tong University Medical School Affiliated Ruijin Hospital Luwan Branch, Shanghai

Ling Wang

Shanghai Jiao Tong University Medical School Affiliated Ruijin Hospital Luwan Branch, Shanghai

Xiao-Yan Fei

Ruijin Hospital

Shu-Ping Xiao

Union Medical College Hospital Affiliated with Huazhong Medical University,Wuhan

Wei-Wei Hou

Third Affiliated Hospital,Shihezi University, Xinjiang

Chun-Hong Li

The First Affiliated Hospital of Guangzhou Sun Yat-sen University,Guangzhou

Hong-Yan Shao

The First Affiliated Hospital of Guangzhou Sun Yat-sen University,Guangzhou

\section{Research Article}

Keywords: Transjugular intrahepatic portosystemic shunt (TIPS), Transitional care, Compliance behaviors, Hepatic function.

Posted Date: March 17th, 2021

DOl: https://doi.org/10.21203/rs.3.rs-154444/v1

License: (c) (i) This work is licensed under a Creative Commons Attribution 4.0 International License. Read Full License 


\section{Abstract}

Background:To explore the application effect of multicenter transitional nursing in patients post-TIPS.

Methods:A total of 368 patients who underwent TIPS were randomly allocated to the control or intervention group. Patients in the control group received conventional care, and patients in the intervention group received conventional care combined with transitional care. The Child-Pugh scores, blood ammonia levels, compliance behavior, medication compliance, and adverse event incidence rates in the two groups were compared at 1, 3, 6, 9 and 12 months postTIPS.

Results:Repeated measures analysis of variance showed significant group effects 1, 3, 6, 9 and 12 months post-TIPS in the compliance behavior scores of the two groups. The intervention group had significantly higher compliance behavior scores than the control group 1, 3, 6, 9 and 12 months post-TIPS. The incidence of postoperative adverse events in the intervention group was significantly lower than that in the control group 12 months after TIPS. The group effects, time effects and group*time interaction revealed significant differences in the Child-Pugh scores 1, 3, 6, 9 and 12 months post-TIPS between the two groups and significant differences in blood ammonia levels 9 months after TIPS.

Conclusions:Post-TIPS transitional care interventions increased patients'access to scientifically informed nursing, significantly improved patients'compliance behavior and health, and decreased the incidence of postoperative adverse events.

\section{Background}

Transjugular intrahepatic portosystemic shunt (TIPS) is an important option for the management of complications of portal hypertension in patients with cirrhosis caused by various etiologies. ${ }^{1}$ TIPS is an effective emergency treatment for esophageal variceal bleeding in patients who have failed conventional therapy. ${ }^{2}$ Although TIPS can effectively resolve problems associated with portal hypertension, prognostic evaluation of complications has also become critical. Most patients who undergo TIPS leave the hospital immediately after treatment, but they still need diet-related guidance and long-term anticoagulant and hepatoprotective treatment after discharge. Studies have shown that the initial period after discharge from the hospital is a dangerous one in which treatment is not continued properly or adverse events occur. ${ }^{3,4}$ How to help patients master effective postdischarge self-management skills to improve their symptoms and prognosis, reduce complications, and improve quality of life is an important issue requiring the attention of both doctors and patients.

Transitional care intervention programs are usually multidisciplinary in nature and aimed at improving health care provider outcomes through improvements in care coordination and continuity for patients during the transition between health care settings. ${ }^{5}$ The theoretical concept underlying transitional care interventions is that readmissions are largely preventable if issues that predispose patients to return to the hospital for treatment can be addressed. ${ }^{6}$ Transitional care intervention programs have been targeted at patients with specific diagnoses ${ }^{7,8}$ or focused on general medical patients with an average risk of readmission. ${ }^{9,10} \mathrm{~A}$ new model of specialized caregiving that is based on a series of diagnostic imaging procedures performed in real time and on the integrated activity of consultant hepatologists in outpatient departments, dedicated nurses, physicians in training, and primary physicians has reduced the rates of 30-day readmission and 12-month mortality in patients with cirrhosis and ascites. ${ }^{11}$ There have been few well-designed studies supporting the effectiveness of transitional care for patients with portal hypertension post-TIPS, primarily due to the multifaceted nature of portal hypertension complications and the difficulty of performing randomized controlled studies (RCTs) on transitional care interventions.

Therefore, it is imperative to establish a transitional care intervention model for patients who have undergone TIPS that is suited to China's national conditions and medical and health system. ${ }^{12,13}$ Based on comprehensive consideration of the representative regional hospitals nationwide, their comprehensive nursing capacity, and the number of TIPS procedures completed per calendar year, seven hospitals were selected to form a TIPS continued nursing multicenter study group for a multicenter RCT of the implementation of continued care for post-TIPS patients.

We conducted an RCT to determine whether multidisciplinary and patient-centered transitional care interventions for patients with post-TIPS would improve compliance behavior and reduce complications post-TIPS. We hypothesized that:

1) Patients referred to transitional care interventions would have significantly higher total scores for compliance behavior associated with complications postTIPS than the control group.

2) Patients referred to transitional care interventions would exhibit a significantly lower incidence of adverse events.

3) Patients who experienced transitional care interventions would exhibit significantly greater improvement in their Child-Pugh scores and blood ammonia levels post-TIPS than the control group.

\section{Patients And Methods}

\section{Study design}

The study protocol was approved by the ethical committees for human investigations at Ruijin Hospital Luwan Branch, Shanghai Jiao Tong University School of Medicine, and by the Local Department of Health and Family Planning Commission. The study protocol also fulfilled the guidelines of Good Clinical Practice in clinical trials. The study was registered in an independent clinical trial database (www.clinicaltrials.gov; identifier: NCT02877953)(08/24/2016). The purpose of the study, enrollment, follow-up, and the details of the TIPS operation were explained to all the patients, and written informed consent was obtained. All data were recorded on regularly monitored case report forms that were entered into a database by the same investigator. All authors had access to the study data and reviewed and approved the final manuscript. 


\section{Study population}

This study was conducted based on open recruitment and review by the research group, and a multicenter joint research agreement was signed with several hospitals. The research group held a discussion and selected 7 interventional departments in hospitals in 5 cities to participate in this study after considering regional distribution, hospital scale, comprehensive nursing capacity and other factors. Among them, 1 hospital dropped out for an unexplained reason; therefore, 6 hospitals participated in the research.

A total of 368 patients who underwent TIPS surgery in the 7 hospitals from September 2018 to September 2019 were selected as the study subjects.

The study inclusion criteria were as follows:

- Clinical diagnosis of portal hypertension

- Child-Pugh score冈10

- TIPS surgery was successful and the patient had no cognitive impairment

- Informed consent

The study exclusion criteria were as follows:

- Age $<18$ years

- Right ventricular failure

- Severe systemic infection

- Hepato cellular carcinoma (HCC)

- Terminal disease

- Failure to provide written consent to participate in the study

- Unreachable region.

\section{Randomization}

The patients were numbered in order, and they were divided into an intervention group and a control group by the random number table method, with 184 patients in each group. Among them, 23 patients in the intervention group withdrew from this study for personal reasons, 5 patients in the control group withdrew from this study for personal reasons. All patients were followed for a period of at least 12 months or until death.

\section{Control group}

During each patient's hospital stay, the transition nurses created a transitional care file that included information on the patient (inpatient medical and nurse care plan and medications) and the discharge plan, which included the scheduled regular return visits (1, 3, 6, 9 and 12 months post-TIPS) and information on how to prevent gastrointestinal bleeding, infection, and constipation; how to eat a quality low-protein diet; how to recognize minimal HE; how to monitor blood ammonia levels; and how to deal with adverse drug reactions to anticoagulants. An evidence-based transitional care handbook with all these details was given to the participants post-TIPS.

On the day of discharge of the patient from the hospital,a transition nurse met with the patient to review the follow-up recommendations. The transition nurse verified that the medications were prescribed in accordance with the discharge plan and that the patient and his/her caregiver understood the anticoagulant, liver-protective agent, and lactulose prescriptions and were informed of the planned appointments and the blood biochemistry monitoring.

Twelve months after hospital discharge, a transition nurse followed-up with the patient once a month by telephone.

\section{Interventions}

In addition to receiving the same care as the control group, the patients in the intervention group received transitional care interventions provided by a multidisciplinary team composed of dedicated nurses, transition nurses, physicians and computer information engineers in training, and primary physicians by telephone follow-up, family visits, and WeChat guided online sessions. Before discharge, the transition nurses provided the patients with kitchen scales to facilitate the maintenance of a high-quality low-protein diet.

\section{Telephone follow-up:}

Each telephone follow-up lasted approximately 10-15 minutes and was implemented within 72 hours after the patient was discharged. Follow-up phone calls occurred at 2 and 4 weeks, followed by once a month thereafter. Dedicated nurses were informed of the symptoms of the patients, the presence of complications, and the psychological state of the patients, and they provided specific guidance for addressing complications and consulted primary care physicians when necessary. Participants with serious complications were admitted to the hospital. The frequency of telephone follow-ups increased as appropriate.

\section{Family visit:}

Family visits were carried out for the patients who did not return regularly for visits 1, 3, 6, 9 and 12 months after discharge. Each visit lasted between 30 and 45 minutes. Dedicated nurses assessed the patient's health status, including his or her vital signs; monitored blood ammonia through a portable blood 
ammonia detector; and helped patients master simple nursing procedures, such as white vinegar(the main ingredient of white vinegar is acetic acid, which reduces the absorption of blood ammonia)clysis.

\section{Network communication platform}

The WeChat platform was used to strengthen communication between the subjects and the multidisciplinary team. Timely online guidance for patients could also be provided. Nursing staff collected knowledge related to post-TIPS rehabilitation and produced pictures and videos for release with the assistance of computer technicians. The frequency of information release was at least twice a week. The theme for the first week of each month was basic knowledge of TIPS and psychological counseling. The theme for the second week was attention to medication after TIPS and prevention of complications. The theme for the third week was healthy diet recommendations and exercise instruction. The theme for the fourth week was the requirements for follow-up visits and matters needing attention, and the data were collected and released in this order each month. Transition nurses and physicians were available online to guide patients every Tuesday and Friday night from 20:30 to 21:30. In addition, comments were made on the problems with patients' communication in the group on that day, and incorrect cognition was pointed out and corrected in a timely manner.

\section{Intervention content}

(1)The prevention of risk factors for hepatic encephalopathy(HE)

Diet cards were custom-made to prevent gastrointestinal bleeding based on an evaluation for esophageal gastric varices. Patients were given guidance on how to prevent infection of the upper respiratory tract, digestive tract, and wound and on how to eat a high-quality low-protein diet. Minimal HE was evaluated based on symptom recognition, the digit symbol test, and the number connection test-A. The multidisciplinary team focused on identifying the cause of infection and took appropriate and timely measures, such as the administration of medication by an oral route or local application, diet adjustment, and white vinegar clysis, to prevent and treat constipation. It was important for the participants to make regular return visits so that their blood ammonia levels could be monitored.

\section{(2)The prevention of shunt stenosis and occlusion}

We urged patients to regularly undergo Doppler ultrasound so that shunt stenosis could be detected early and measures could be taken in a timely manner. During the short-term postoperative anticoagulation period, additional effort was also made to prevent adverse drug reactions associated with anticoagulant medication.

(3)Adverse anticoagulant drug reaction prevention guidance

To evaluate patients' medication adherence and improve compliance, praise was given in the WeChat group, and in advanced cases, progress was shared with ward mates. Patients who missed a dose or stopped taking their medication were assisted by nurses who sent WeChat medication reminders to improve the medication adherence rate.

(4)Psychological guidance

The psychological status of patients was evaluated. If anxiety, depression or other negative emotions were detected, targeted intervention was conducted to encourage patients to participate in more social activities or communicate more with patients in the patient group to build their confidence. Furthermore, patients' family members were guided to strengthen their support for the patients.

\section{Data collection}

Subjects were followed for 12 months or more postdischarge to monitor their clinical symptoms. The collected data included the following: (1) Demographic characteristics. (2) Compliance behavior. (3) Clinical data, including cirrhosis etiology; the results of routine blood tests, coagulation tests, and hepatic function tests (Child-Pugh score); blood ammonia levels; and the results of color ultrasound, CT scans, and/or gastroscopy. Ultrasonography was repeated monthly to exclude shunt dysfunction. (4) Adverse events, such as HE, TIPS dysfunction, readmission details, and death. The latter were recorded in a new database.

\section{Primary Outcome Measures:Compliance Behavior}

Time period: 1, 3, 6, 9 and 12 months after discharge

The compliance behaviors of post-TIPS patients were surveyed using a self-designed questionnaire. The questionnaire included reminders to take medicine on time, eat a high-quality and low-protein diet, go to sleep at a regular time, engage in moderate exercise, regulate emotions, and attend regular follow-ups. Item responses were documented based on a 4-point scale ( $0=$ never to $3=$ always). Total scores ranged from 0 to 18 , with higher scores indicating better compliance. Data were collected via face-to-face interviews with trained transition nurses.

\section{Secondary Outcome Measures:}

Time period: 12 months after discharge

(1)Incidence of adverse events: The incidence of postoperative adverse events, including shunt stenosis, the recurrence of clinical symptoms associated with portal hypertension, adverse drug reactions and mortality, was compared between the two groups.

Page $4 / 12$ 
Time period: Baseline, 1, 3, 6, 9 and 12 months after discharge

(2)Child-Pugh scores and blood ammonia levels.

\section{Compliance with ethical standards}

The measures taken to ensure the quality of the research included the following: (1) All subjects were willing to participate in the research and signed written informed consent forms, and they were promised that the research results would be used only for academic research and did not involve personal rights and interests. (2) The data related to the research objects were kept strictly confidential and were read and stored by the researchers. (3) All members of the research group participating in the study received unified training and passed a written examination, and they all used the same guidance language during the investigation. (4) All the recovered data were coded and sorted, uploaded to the database independently by the researchers, and checked for logical errors.

In addition, to avoid possible bias caused by the multicenter nature of the research, a quality control group was set up. The heads of each research unit and the head nurse of the unit department jointly formed a quality inspection group. During the study period, the consistency and accuracy with which the research scheme was implemented by the participating nurses were randomly checked monthly; when problems were found, timely guidance and correction were given. The project leader used WeChat and telephone contact to organize a quality control group discussion once a quarter. The discussion focused on the consistency and accuracy with which the research plan was implemented by each research unit and on the formulation of countermeasures for joint implementation. The collected research data were examined and approved by the research leader of each unit and submitted to the research group immediately.

\section{Statistics}

Statistical analyses were conducted using SPSS version 20.0 (Chicago, IL, United States). The summary statistics for the continuous variables are presented as the means with standard deviations or standard errors of the mean for comparison tests. Proportions are used for the categorical variables.

The chi-square test was used to determine the differences in proportions. Continuous variables were compared with the unpaired Student's $t$ test (or the nonparametric Mann-Whitney rank-sum test, when required) and repeated measures analysis of variance(RM ANOVA).Patients were considered lost to followup if they did not attend two consecutive 12-month clinical examinations. Statistical significance was established at a $P$ value $<0.05$.

\section{Results}

\section{Baseline Characteristics}

Between 2018 and 2019, 368 patients who had previously undergone TIPS were identified and enrolled in the study. The demographic and procedural data for the entire population and a comparison based on the Child-Pugh scores are summarized in Table 1. Table 1 shows no statistically significant differences between the two groups in terms of sex; age; education; number of children; occupation; income; etiology; or severity of liver disease, including Child-Pugh scores and blood ammonia levels $(P>0.05)$. 7 participants died and 23 were lost to follow-up in the intervention group. 16 participants died and 5 were lost to follow-up in the control group (Figure 1).

\section{Primary Outcome Analysis}

The medical compliance scores for the two groups of patients at 1, 3, 6, 9 and 12 months post-TIPS are shown in Table 2. As shown in conjunction with Table 3 , the intervention group performed significantly better than the control group in terms of medication compliance, diet, regular sleep, emotion regulation, and regular follow-up compliance $(P<0.001)$. In addition, the results of RM ANOVA also proved that there was an interaction effect between the follow-up time of patients after discharge and the above outcome indicators. As the postoperative follow-up time lengthened, the compliance of patients in the two groups increased at different rates, and this change was more significant in the intervention group (Table 4).

\section{Secondary Outcome Measures}

As shown in Table 5, within 12 months post-TIPS, the incidence of adverse events in the intervention group (15.53\%, 25/161) was significantly lower than that in the control group $(32.96 \%, 59 / 179), \mathrm{c} 2=10.47, P<0.05$, and the difference was statistically significant.

\section{Secondary Outcome Measures}

The results of RM ANOVA showed that the Child-Pugh scores and blood ammonia levels followed different trends across time points in the two groups $(P<0.001)$. There were statistically significant differences in the Child-Pugh scores between the groups of patients treated by different nursing methods, and patients in the intervention group had significantly better scores than those in the control group $(P<0.05)$. The blood ammonia levels showed no statistically significant difference between groups at 1,3, and 6 months post-TIPS, but there was a statistically significant difference between the two groups at 9 and 12 months post-TIPS $(P<0.05)$ (Table 3$)$. The results of RM ANOVA also proved the effect of patients'follow-up time after discharge and the interaction effect between group and time. With a longer duration of postoperative follow-up, in both groups of patients, the Child-Pugh scores and blood ammonia levels decreased, but the patients in the intervention group showed more significant improvement, as the blood ammonia level in the control group reached its nadir at 3 months post-TIPS and increased thereafter (Table 4).

\section{Discussion}


TIPS insertion is an effective method for resolving the symptoms of portal hypertension. ${ }^{14,15}$ After TIPS insertion, the portal vein blood flow to the liver is reduced, and the hepatic artery blood flow increases to compensate for this reduction ${ }^{16,17}$ because of the interdependence of the portal vein and hepatic artery. However, increases in the symptom recurrence rate and the incidence of $\mathrm{HE}$, which may adversely affect quality of life and accelerate liver function deterioration, are the main causes of death post-TIPS. ${ }^{18}$ In fact, HE is very frequent following TIPS insertion and may be persistent and refractory to medical treatment in a minority of patients, thus significantly affecting quality of life. ${ }^{19}$ Therefore, efforts at discharge must focus on this high-risk group of patients to decrease the incidence rate of post-TIPS complications.

In recent years, the 30-day readmission rate of patients after discharge post-TIPS has been as high as $20 \%{ }^{20}$ Studies have shown a patient compliance rate of only $37.45 \%$ after discharge; a lack of compliance makes it difficult for patients and their families to implement correct postoperative care. In the Central Committee of the Communist Party of China and the State Council's"Opinions on deepening the reform of the medical health system"it states, "Continuing care will be an important approach to chronic disease management" ${ }^{21}$. The document identifies the main objectives of providing continuous, coordinated and holistic care services to the elderly and those with chronic diseases. A recent single-center study of patients with cirrhosis showed that a multidisciplinary transitional care approach that included managing cirrhosis complications and ensuring optimal follow-up and prompt communication with outpatient teams not only reduced readmissions but also improved overall mortality. ${ }^{22}$ Consistent with this report, the results of the present study suggest that transitional care interventions provided by a multidisciplinary team can improve compliance behavior and decrease the incidence of HE and shunt dysfunction 12 months postTIPS. In this study, patients who received transitional care interventions from a multidisciplinary team reported significantly higher compliance behavior scores. The intervention group had better compliance in terms of maintaining a high-quality low-protein diet, taking medicine on time, going to sleep at a regular time, engaging in moderate exercise, regulating emotions and attending regular follow-up at three time points post-TIPS.

Because patients are vulnerable soon after leaving the hospital, postdischarge telephone calls, which are an important part of care transitions, may improve clinical outcomes. ${ }^{23}$ Some studies have shown improvement in outcomes such as knowledge, adherence, satisfaction, emergency department (ED) visits, and readmissions. ${ }^{24,25}$ According to these studies, increased compliance scores were associated with a decreased risk of adverse events. Consistent with these reports, the results of the present study also showed that transitional care interventions can dramatically decrease the incidence of HE and shunt dysfunction. To improve clinical outcomes post-TIPS, transitional care interventions may be an important initiative worth considering.

The establishment of shunt channels in TIPS procedures reduces the perfusion of portal blood flow to the liver, which affects the liver function of patients. ${ }^{26}$ The results of this study showed that following the operation, regular doses of liver-protecting drugs, maintenance of a stable mood, attention to diet and regular rest and rest can promote the recovery of liver function.

After shunt placement, patients with cirrhosis are prone to develop hyperammonemia, which leads to HE. Once clinical HE develops, the fatality rate is as high as $50 \%$. Early prevention and treatment of minimal HE can improve the patient's knowledge and ability to work and live and help prevent the further development of clinical HE. ${ }^{27,28}$ In the process of continuing nursing care post-TIPS, the group members increased the number of blood ammonia tests of patients in the intervention group through family visits and helped the patients to identify abnormalities and address the cause in a timely manner, and hospitalized treatment was provided when necessary. Therefore, although continued nursing cannot significantly reduce the blood ammonia level of patients in the early stage after TIPS, it can reduce the incidence of postoperative HE through long-term monitoring and nursing management measures.

In China, continued nursing after interventional surgery involves the interventional treatment of patients with advanced liver cancer receiving arterial infusion chemotherapy or patients with lower extremity occlusive sclerosis. ${ }^{29,30}$ In particular, studies on continued nursing interventions after TIPS are still in the exploratory stage, and no consensus has been reached. The post-TIPS intervention in this postoperative multicenter study reflected current trends in information services by using the WeChat platform to establish a group chat for learning about patients' needs in real time and providing timely nursing instruction and guidance in response, allowing patients to learn about the disease anytime and anywhere. The manual post-TIPS extended nursing intervention is more suitable for elderly patients who are not familiar with modern technology. Combined with regular telephone follow-up, the multiplatform and diversified health education methods provided a supportive and comprehensive nursing environment for the rehabilitation of patients after TIPS. ${ }^{31,32}$

\section{Abbreviations}

TIPS:Transjugular intrahepatic portosystemic shunt;HE:hepatic encephalopathy.

\section{Declarations}

\section{Acknowledgements}

Not Applicable.

\section{Authors' contributions}

X.Y.,H.W. and Y.R. contributed equally to this work. H.W. and Y.R. conceived the study and developed the contents of the evidenced-based transitional care handbook post-TIPS.X.Y.,H.W.,X.S.,Q.D.,L.C.,S.H.and F.X.carried out the patient recruitment and coordinated the study.X.Y.,H.W.,X.S.,Q.D.,L.C.,S.H.and Y.R. participated in the transitional care intervention follow-ups. X.Y., H.W. and W.L. completed the statistical analyses and wrote the manuscript. W.Z. participated in the design of the study and assisted in drafting the manuscript. All authors read and approved the final manuscript.

Funding 
This work was supported by the Foundation of the Shanghai Public Health Bureau, No. 201740143 and the Project of Medical Key Specialty of the Shanghai Municipal Health Commission, No. ZK2019A02.

\section{Availability of data and materials}

The datasets generated and/or analyzed in the present study are available from the corresponding author on reasonable request.

\section{Ethics approval and consent to participate}

The study protocol also fulfilled the guidelines of Good Clinical Practice in clinical trials. The study was registered in an independent clinical trial database (www.clinicaltrials.gov; identifier: NCT02877953)(08/24/2016).All authors had access to the study data and reviewed and approved the fnal manuscript.

\section{Declaration}

The purpose of the study, enrollment, follow-up, and the details of the TIPS operation were explained to all the patients, and written informed consent was obtained.

\section{Consent for publication}

Not Applicable.

\section{Competing interests}

The authors declare that they have no competing interests.

\section{Author details}

a Department of Nursing, Shanghai Jiao Tong University Medical School Affiliated Ruijin Hospital Luwan Branch, Shanghai 200020,China;b Department of Nursing, The Third Affiliated Hospital,Shihezi University, Xinjiang 832000, China;c Department of Interventional Radiology, Shanghai Jiao Tong University Medical School Affiliated Ruijin Hospital, Shanghai 200025,China;d Department of Nursing,Union Medical College Hospital Affiliated with Huazhong Medical University,Wuhan 430022,China;e Department of Nursing,The First Affiliated Hospital of Guangzhou Sun Yat-sen University,Guangzhou 510080,China;f Department of Nursing,Affiliated Cancer Hospital of Guangzhou Sun Yat-sen University,Guangzhou 510060,China.

\section{References}

1 Chinese College of Interventionalists.CCI clinical practice guidelines: management of TIPS for portal hypertension (2019 edition)[J].Zhonghua Gan Zang Bing Za Zhi,2019,35(12):2694-2699[PMID: 31594075 DOI: 10.3760/cma.j.issn.1007-3418.2019.08.002]

2 Pereira K,Carrion A F,Salsamendi J,et al.Endovascular management of refractory hepatic encephalopathy complication of transjugular intrahepatic portosystemic shunt (TIPS):comprehensive review and clinical practice algorithm[J].Cardiovasc Intervent Radiol,2016,39(2):170-182[DOI:10.1007/s00270-015$1197-x]$

3 Shaojie Wu,Yicheng Wu,Yanfu Shen,et al.Transjugular intrahepatic portosystemic shunt plus embolization for bleeding esophagojejunal varices after total gastrectomy[J].Journal of Interventional Medicine,2(2019):181-183[DOI:10.1016/j.jimed.2019.10.005]

4 Chen Dongping,Xiao Shuping,Ge Yan,Liu Xiao.Application of standardized transitional care in patients after transjugular intrahepatic portosystemic shunt[J].Journal of nursing, 2018,33(23):80-81+94[DOI:10.3870/j.issn.1001-4152.2018.23.080]

5 Stephens Caroline,Sackett Nathan,Pierce Read,et al.Transitional care challenges of rehospitalized veterans: listening to patients and providers[J].Population Health Management,2013,16(5):326-31[DOI:10.1089/pop.2012.0104]

6 Sezgin Duygu,O'Caoimh Rónán,Liew Aaron,et al.The effectiveness of intermediate care including transitional care interventions on function, healthcare utilisation and costs: a scoping review[J].Eur Geriatr Med,2020(11):961-974[DOI:10.1007/s41999-020-00365-4]

7 Morkisch Nadine, UpeguiArango Luz D,Cardona Maria I,et al.Components of the transitional care model(TCM) to reduce readmission in geriatric patients: a systematic review[J].BMC Geriatr,2020,20(1):345-345[DOI:10.1186/s12877-020-01747-w]

8 Parker Kirsten J,Hickman Louise D,Phillips Jane L,Ferguson Caleb.Interventions to optimise transitional care coordination for older people living with dementia and concomitan tmultimorbidity and their caregivers: A systematic review[J].Contemp Nurse,2020,1-29[D0I:10.1080/10376178.2020.1812416]

9 Ravelli Angelo,Sinigaglia Luigi,Cimaz Rolando,et al.Transitional care of young people with juvenile idiopathic arthritis in Italy: results of a Delphi consensus survey[J].Clin.Exp.Rheumatol,2019,37(6):1084-1091[PMID:31376254]

10 Sabina B.Gesell,Cheryl D.Bushnell,Sara B.Jones,et al.Implementation of a billable transitional care model for stroke patients:the COMPASS study[J].BMC Health Serv Res,2019,19(3):e38-360[DOI:10.1186/s12913-019-4771-0]

11 J.S.Bajaj,K.R.Reddy,G.Garcia-Tsao,et al.P0120:The 3-month readmission rate remains unacceptably high in a large multi-center cohort of cirrhotic patients[J].Journal of Hepatology,2015,62:S345-S346[DOI:10.1016/S0168-8278(15)30340-8]

Page $7 / 12$ 
12 Jiang MM,Xu H,Zhang QQ,Wei N,et al,Preliminary application of transjugular intrahepatic portosystemic shunt in individualized treatment of patients with cirrhotic portal hypertension complicated with refractory ascites and variceal hemorrhage[J].Zhonghua Yi Xue Za Zhi,2019(47):3737-

3740[DOI:10.3760/cma.j.issn.0376-2491.2019.47.012]

13 Wan QJ,Hou WW,Cheng WL,Wang ZM.Study on transitional care intervention of patients after TIPS[J].Journal of interventional radiology,2016,25(12):1041108 [DOI:10.3969/j.issn.1008-794x.2016.12.020]

14 Barnes-Daly Mary Ann,Pun Brenda T,Harmon Lori A,et al.Improving Health Care for Critically III Patients Using an Evidence-Based Collaborative Approach to ABCDEF Bundle Dissemination and Implementation[J].Worldviews Evid Based Nurs,2018,15(3):206-216[D0I:10.1111/wvn.12290]

15 Liu L,Zhao Y,Qi X,Cai G,He C,Guo W,et al.Transjugular intrahepatic portosystemic shunt for symptomatic portal hypertension in hepatocellular carcinoma with portal vein tumor thrombosis[J].Hepatol Res,2014,44:621-630[DOI:10.1111/hepr.12162]

16 Stankovic Z,Rössle M,Euringer W,Schultheiss M,Salem R,Barker A,et al.Effect of TIPS placement on portal and splanchnic arterial blood flow in 4dimensional flow MRI[J].

EurRadiol,2015,25:2634-2640[DOI:10.1007/s00330-015-3663-x]

17 Zhang K.The clinical characteristics of cirrhosis with portal vein thrombosis and the clinical application of transjugular intrahepatic portosystemic shunt[D].Shandong University,2019.

18 Qiu B,Zhao MF,Yue ZD,Zhao HW,Wang L,Fan ZH,et al.Combined transjugular intrahepatic portosystemic shunt and other interventions for hepatocellular carcinoma with portal hypertension[J].World J Gastroenterol,2015,21:12439-12447[DOI:10.3748/wjg.v21.i43.12439]

19 Nardelli S,Gioia S,Pasquale C,Pentassuglio I,Farcomeni A,Merli M,et al.Cognitive impairment predicts the occurrence of hepatic encephalopathy after transjugular intrahepatic portosystemic shunt[J].Am J Gastroenterol,2016,111:523-528[DOI:10.1038/ajg.2016.29]

20 Jha.A K,Joynt K E,Orav E J.et al.The long-term effect of premier pay for performance on patient outcomes[J].N Engl J Med,2012,366(17):1606-1615[DOI8 0.1002/14651858.CD011156.pub2]

21 Leigh C.Casadaban, Ahmad Parvinian, Jeet Minocha,et al.Clearing the Confusion over Hepatic Encephalopathy After TIPS Creation:Incidence,Prognostic Factors,and Clinical Outcomes[J].Dig Dis Sci,2015,60(4):1059-1066[DOI:10.1007/s10620-014-3391-0]

22 Fei JJ,Zhou W,Xu ML,Zhang LJ.Effect of continuous nursing based on Omaha system on quality of life and negative emotion in patients with liver cirrhosis after transjugular intrahepatic portosystemic shunt[J].Chinese Journal of Modern Doctors,2020,58(13):170-174[D0l:1673-9701(2020)13-0170-05]

23 Record JD,Niranjan-Azadi A,Christmas C,Hanyok LA,Rand CS,Hellmann DB,et al. Telephone calls to patients after discharge from the hospital: an important part of transitions of care[J].Med Educ Online,2015,20:26701[DOI:10.3402/meo.v20.26701]

24 Zhou BY,Li XL,Huang XX,et al.Telephone Follow-up Design and Practice for Advanced Cancer Pain Patients[J].J Cancer Education,2020,35(4):751759[DOI:10.1007/s13187-019-01523-4]

25 Zhang Y,Li GH,Liu M.Current situation and Suggestions of continuing nursing care for discharged surgical patients in China[J].Chinese Journal of Nursing,2016,51(4):409-412[DOI:10.3761/j.issn.0254-1769.2016.04.005]

26 Wang N,Li J,Li X,Liang LW,et al.The development and application of a risk prediction model for hepatic encephalopathy in patients with liver cirrhosis[J].Chinese Journal of Nursing,2019,54(6):805-811[DOI:10.3761/j.issn.0254-1769.2019.06.001]

27 Cheng XY.Clinical application of shunt restriction in the treatment of hepatic encephalopathy after transjugular intrahepatic portosystemic shunt[D].Shandong University,2019.

$28 \mathrm{Li}$ YL.Establishment and validation of clinical prediction models in patients with early hepatic encephalopathy under going transjugular intrahepatic portal shunt[D].South University of Science and Technology,2019.

29 Hua GR,Zhong CP,Peng AM.Application of multidisciplinary collaborative diagnosis and treatment mode in nursing care of patients with primary liver cancer and portal hypertension treated by TIPS[J].Chinese general practice nursing,2019,17(16):1998-2000[D0I:10.12104/j.issn.1674-4748.2019.16.030]

30 Chen D,Feng GS,Lin MG,et al.Application of transitional care mode in anemia patients after interventional treatment of gastrointestinal hemorrhage[J].Journal of interventional radiology, 2016,25(3):264-267.doi:10.3969/j.issn.1008-794x.2016.03.020.

31 Zhang L,Zhou XL,Zhu J,Zhang LN.Study on the application of transitional care in patients discharged from hospital after TIPS[J].Journal of Nurses Traning,2017,32(18):1701-1703[DOI:10.16821/j.cnki.hsjx.2017.18.024]

32 Zhang HM,Qian X,Pan BY.Influence of wechat combined with family visit transitional care on medical compliance and quality of life of patients after TIPS[J].Journal of Qiqihar University of Medicine,2018,39(10):1234-1236[DOI:10.3969/j.issn.1002-1256.2018.10.053]

\section{Tables}


Table 1 Comparison of the baseline characteristics of the post-TIPS patients between the control and intervention groups.

\begin{tabular}{|c|c|c|c|c|}
\hline ariable & Interventio & Control group $(n=179)$ & $t / \mathrm{c}^{2} \mathrm{val}$ & $p$ value \\
\hline$\overline{e x}$ & & & 0.038 & 0.846 \\
\hline Tale & 127 & 136 & & \\
\hline 'emale & 34 & 43 & & \\
\hline ge & & & 0.032 & 0.858 \\
\hline Inder the age of 35 & 10 & 12 & & \\
\hline $5 \sim 45$ & 27 & 26 & & \\
\hline $6 \sim 55$ & 38 & 42 & & \\
\hline $6 \sim 65$ & 26 & 34 & & \\
\hline lder than 65 & 26 & 31 & & \\
\hline 'ducation (highest & & & 0.283 & 0.595 \\
\hline ualification) & & & & \\
\hline literate & 24 & 26 & & \\
\hline rimary school & 26 & 33 & & \\
\hline ınior high school & 58 & 57 & & \\
\hline Iigh school or technical secondary school & 138 & 44 & & \\
\hline Iniversity and above & 15 & 19 & & \\
\hline Iccupation & & & 0.020 & 0.888 \\
\hline Inemployed & 7 & 9 & & \\
\hline armers & 32 & 37 & & \\
\hline Vorkers & 29 & 24 & & \\
\hline rofessional technical personnel & 11 & 11 & & \\
\hline ther & 82 & 98 & & \\
\hline Jumber of children & & & 1.051 & 0.306 \\
\hline & 85 & 109 & & \\
\hline-3 & 42 & 35 & & \\
\hline Tore than 3 & 23 & 25 & & \\
\hline Jone & 11 & 10 & & \\
\hline ncome & & & 0.519 & 0.472 \\
\hline Jone & 10 & 18 & & \\
\hline ess than 2000 yuan & 43 & 37 & & \\
\hline 000-3000 yuan & 32 & 35 & & \\
\hline 000-4000 yuan & 33 & 38 & & \\
\hline 000-5000 yuan & 18 & 24 & & \\
\hline bove 5000 yuan & 25 & 27 & & \\
\hline 'tiology & & & 1.420 & 0.234 \\
\hline irrhosis & 78 & 89 & & \\
\hline Ipper GI bleeding & 41 & 53 & & \\
\hline Iepatic malignant tumors & 27 & 17 & & \\
\hline sophageal and gastric varices & 9 & 11 & & \\
\hline udd-Chiari syndrome & 4 & 2 & & \\
\hline ther & 2 & 7 & & \\
\hline 'hild-Pugh score post-TIPS & $8.5 \pm 0.76$ & $8.75 \pm 1.48$ & 0.191 & 0.667 \\
\hline lood ammonia & $9.93 \pm 3.36$ & $9.22 \pm 2.20$ & 0.715 & 0.480 \\
\hline
\end{tabular}

Table 2 Basic medical compliance in the post-TIPS patients between the control and intervention groups. 


\begin{tabular}{|c|c|c|c|c|c|}
\hline$\overline{\mathrm{m} / \text { Group }}$ & 1 month post-TIPS & 3 months post-TIPS & 6 months post-TIPS & 9 months post-TIPS & 12 months post-TIPS \\
\hline \multicolumn{6}{|c|}{ edication compliance } \\
\hline ontrol group & $1.01 \pm 0.1$ & 1 & $1.01 \pm 0.09$ & $1.01 \pm 0.09$ & 1 \\
\hline itervention group & $1.45 \pm 0.58$ & $1.86 \pm 0.57$ & $2.19 \pm 0.66$ & $2.31 \pm 0.68$ & $2.28 \pm 0.72$ \\
\hline \multicolumn{6}{|l|}{ et control } \\
\hline ontrol group & $1.70 \pm 0.82$ & $1.70 \pm 0.77$ & $1.73 \pm 0.52$ & $1.73 \pm 0.46$ & $1.74 \pm 0.82$ \\
\hline itervention group & $2.07 \pm 0.82$ & $2.65 \pm 0.56$ & $2.66 \pm 0.78$ & $2.67 \pm 0.23$ & $2.67 \pm 0.72$ \\
\hline \multicolumn{6}{|c|}{ gular work and rest } \\
\hline ontrol group & $1.17 \pm 0.65$ & $1.18 \pm 0.78$ & $1.19 \pm 0.25$ & $1.21 \pm 0.62$ & $2.20 \pm 0.11$ \\
\hline itervention group & $1.22 \pm 0.75$ & $2.46 \pm 0.64$ & $2.48 \pm 0.83$ & $2.49 \pm 0.56$ & $2.51 \pm 0.13$ \\
\hline \multicolumn{6}{|l|}{ jderate exercise } \\
\hline ontrol group & $1.03 \pm 0.72$ & $1.11 \pm 0.69$ & $2.10 \pm 0.18$ & $2.14 \pm 0.54$ & $2.15 \pm 0.21$ \\
\hline itervention group & $2.15 \pm 0.66$ & $2.31 \pm 0.79$ & $2.38 \pm 0.62$ & $2.42 \pm 0.87$ & $2.43 \pm 0.24$ \\
\hline \multicolumn{6}{|l|}{ notion regulation } \\
\hline ontrol group & $1.59 \pm 0.57$ & $1.56 \pm 0.57$ & $1.59 \pm 0.62$ & $1.61 \pm 0.28$ & $1.63 \pm 0.38$ \\
\hline itervention group & $1.8 \pm 0.66$ & $2.0 \pm 0.63$ & $2.3 \pm 0.43$ & $2.35 \pm 0.58$ & $2.42 \pm 0.65$ \\
\hline \multicolumn{6}{|l|}{ gular follow-up } \\
\hline ontrol group & $1.33 \pm 1.03$ & $1.22 \pm 1.31$ & $1.28 \pm 0.81$ & $1.30 \pm 2.35$ & $1.32 \pm 1.94$ \\
\hline itervention group & $1.57 \pm 1.28$ & $1.95 \pm 1.98$ & $2.02 \pm 0.56$ & $3.45 \pm 1.33$ & $3.69 \pm 1.76$ \\
\hline
\end{tabular}

Table 3 Comparison of Child-Pugh scoresロblood ammonia levels and compliance behavior scores between the control and intervention groups

\begin{tabular}{|c|c|c|c|c|c|c|c|c|c|}
\hline iroup/Time & $\begin{array}{l}\text { Child-Pugh } \\
\text { scores }\end{array}$ & $t$ value & $p$ value & $\begin{array}{l}\text { Blood ammonia } \\
\text { level }\end{array}$ & $t$ value & $p$ value & $\begin{array}{l}\text { Compliance behavior } \\
\text { scores }\end{array}$ & $t$ value & $p$ value \\
\hline $\begin{array}{l}\text { month post- } \\
\text { IPS }\end{array}$ & & -19.38 & 0.047 & & -1.322 & 0.56 & & 22.06 & {$[0.001$} \\
\hline Control group & $9.31 \pm 1.23$ & & & $44.18 \pm 30.44$ & & & $7.09 \pm 0.48$ & & \\
\hline $\begin{array}{l}\text { ntervention } \\
\text { roup }\end{array}$ & $5.81 \pm 1.66$ & & & $39.61 \pm 24.11$ & & & $9.63 \pm 0.84$ & & \\
\hline $\begin{array}{l}\text { months post- } \\
\text { IPS }\end{array}$ & & -19.49 & $\square 0.001$ & & -0.94 & 0.61 & & 33.05 & $\square 0.001$ \\
\hline Control group & $9.4 \pm 1.08$ & & & $40.50 \pm 24.46$ & & & $7.17 \pm 0.47$ & & \\
\hline $\begin{array}{l}\text { ntervention } \\
\text { roup }\end{array}$ & $5.87 \pm 1.78$ & & & $37.32 \pm 29.62$ & & & $12.96 \pm 0.85$ & & \\
\hline $\begin{array}{l}\text { months post- } \\
\text { IPS }\end{array}$ & & -18.62 & {$[0.001$} & & -3.89 & 0.77 & & 29.6 & $\square 0.001$ \\
\hline Control group & $8.74 \pm 0.94$ & & & $38.53 \pm 15.79$ & & & $8.75 \pm 0.83$ & & \\
\hline $\begin{array}{l}\text { ntervention } \\
\text { roup }\end{array}$ & $5.78 \pm 1.57$ & & & $30.02 \pm 19.32$ & & & $13.39 \pm 1.14$ & & \\
\hline $\begin{array}{l}\text { months post- } \\
\text { 'IPS }\end{array}$ & & -37.61 & 0.001 & & -11.71 & $\square 0.001$ & & 50.34 & 0.001 \\
\hline Control group & $8.94 \pm 1.03$ & & & $40.12 \pm 17.65$ & & & $9.68 \pm 0.89$ & & \\
\hline $\begin{array}{l}\text { ntervention } \\
\text { roup }\end{array}$ & $5.19 \pm 0.39$ & & & $19.86 \pm 7.36$ & & & $14.92 \pm 0.76$ & & \\
\hline $\begin{array}{l}2 \text { months post- } \\
\text { IPS }\end{array}$ & & -19.09 & 00.001 & & -17.40 & $\square 0.001$ & & 89.58 & $\square 0.001$ \\
\hline ontrol group & $6.97 \pm 1.13$ & $41.85 \pm 13.7$ & $9.59 \pm 0.91$ & & & & & & \\
\hline $\begin{array}{l}\text { ntervention } \\
\text { roup }\end{array}$ & $5.09 \pm 0.21$ & $17.85 \pm 6.8$ & $15.91 \pm 0.78$ & & & & & & \\
\hline
\end{tabular}

Table 4 Repeated measures analysis of variance of compliance behavior scores, Child-Pugh scores and blood ammonia levels in the control and intervention groups 


\begin{tabular}{|c|c|c|c|c|c|c|c|c|c|c|}
\hline em/Group & $\begin{array}{l}1 \text { month } \\
\text { post-TIPS }\end{array}$ & $\begin{array}{l}3 \text { months } \\
\text { post-TIPS }\end{array}$ & $\begin{array}{l}6 \text { months } \\
\text { post-TIPS }\end{array}$ & $\begin{array}{l}99 \text { months } \\
\text { post-TIPS }\end{array}$ & $\begin{array}{l}12 \text { months } \\
\text { post-TIPS }\end{array}$ & $\begin{array}{l}\text { F values } \\
\text { of } \\
\text { group } \\
\text { effect }\end{array}$ & $P$ values & $\begin{array}{l}F \text { values } \\
\text { of time } \\
\text { effect }\end{array}$ & $P$ values & $\begin{array}{l}\text { F values } \\
\text { of group*time } \\
\text { interaction }\end{array}$ \\
\hline $\begin{array}{l}\text { 'ontrol } \\
\text { oup }\end{array}$ & $6.09 \pm 0.48$ & $6.17 \pm 0.47$ & $7.75 \pm 0.83$ & $7.68 \pm 0.89$ & $8.59 \pm 0.91$ & 3996.29 & $\square 0.001$ & 8468.14 & $\square 0.001$ & 2025.99 \\
\hline $\begin{array}{l}\text { tervention } \\
\text { oup }\end{array}$ & $8.63 \pm 0.84$ & $11.96 \pm 0.85$ & $12.39 \pm 1.14$ & $12.92 \pm 0.76$ & $13.91 \pm 0.78$ & & & & & \\
\hline $\begin{array}{l}\text { lood } \\
\text { nmonia } \\
\text { vel }\end{array}$ & & & & & & 45.19 & $\square 0.001$ & 58.75 & {$[0.001$} & 42.15 \\
\hline $\begin{array}{l}\text { 'ontrol } \\
\text { oup }\end{array}$ & $44.18 \pm 30.44$ & $40.50 \pm 24.46$ & $38.53 \pm 15.79$ & $40.12 \pm 17.65$ & $41.85 \pm 13.7$ & & & & & \\
\hline $\begin{array}{l}\text { hild-Pugh } \\
\text {;ores }\end{array}$ & & & & & & 830.62 & $\square 0.001$ & 229.17 & $\square 0.001$ & 33.27 \\
\hline $\begin{array}{l}\text { 'ontrol } \\
\text { oup }\end{array}$ & $9.31 \pm 1.23$ & $9.4 \pm 1.08$ & $8.74 \pm 0.94$ & $8.94 \pm 1.03$ & $6.97 \pm 1.13$ & & & & & \\
\hline $\begin{array}{l}\text { tervention } \\
\text { oup }\end{array}$ & $5.81 \pm 1.66$ & $5.87 \pm 1.78$ & $5.78 \pm 1.57$ & $5.19 \pm 0.39$ & $5.09 \pm 0.21$ & & & & & \\
\hline
\end{tabular}

Table 5 The incidence of adverse events in the control and intervention groups 12 months post-TIPS

\begin{tabular}{|c|c|c|c|c|c|c|c|c|c|c|c|c|}
\hline \multirow[t]{2}{*}{ oup/Time } & \multirow[t]{2}{*}{$\begin{array}{l}\text { Gingival } \\
\text { Bleeding }\end{array}$} & \multirow[t]{2}{*}{ MelenalHematochezia } & \multirow[t]{2}{*}{ Hematuria } & \multicolumn{5}{|c|}{$\begin{array}{l}\text { Stage of hepatic } \\
\text { encephalopathy }\end{array}$} & \multirow[t]{2}{*}{$\begin{array}{l}\text { Swelling of lower } \\
\text { limbs }\end{array}$} & \multirow[t]{2}{*}{ Fever } & \multirow[t]{2}{*}{$\begin{array}{l}\text { Shunt } \\
\text { stenosis }\end{array}$} & \multirow[t]{2}{*}{ Death } \\
\hline & & & & 0 & 1 & 2 & 3 & 4 & & & & \\
\hline $\begin{array}{l}\text { tervention } \\
\text { oup }\end{array}$ & 4 & 1 & 0 & 0 & 6 & 2 & 1 & 0 & 3 & 1 & 0 & 7 \\
\hline introl group & 7 & 1 & 1 & 1 & 7 & 3 & 1 & 1 & 15 & 4 & 2 & 16 \\
\hline
\end{tabular}

\section{Figures}




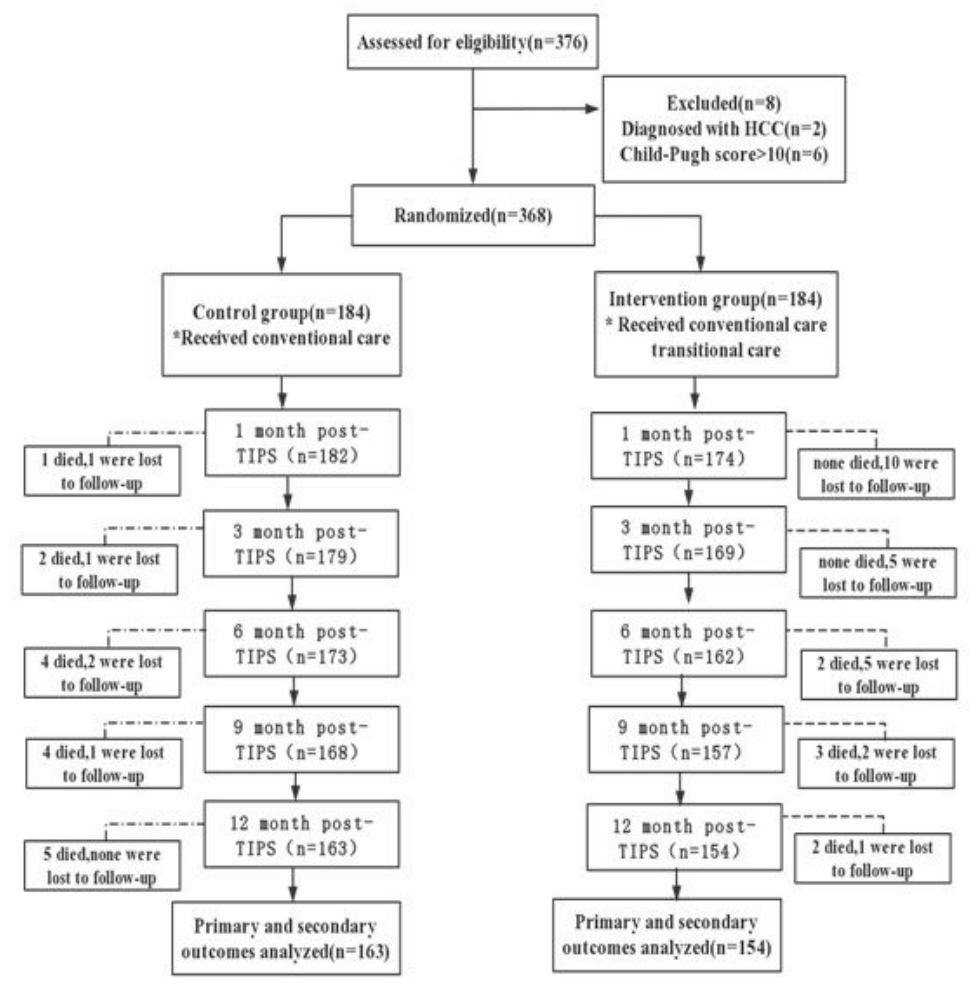

Figure 1

An illustration of the study design.

\section{Supplementary Files}

This is a list of supplementary files associated with this preprint. Click to download.

- TIPStables.docx

- CONSORT2010Checklist.doc 